\title{
Correction to: Accurate estimation of log MOE from non-destructive standing tree measurements
}

\author{
Chandan Kumar ${ }^{1} \cdot$ Steven Psaltis ${ }^{2,3} \cdot$ Henri Bailleres ${ }^{1} \cdot$ Ian Turner ${ }^{2,3} \cdot$ Loic Brancheriau $^{4} \cdot$ Gary Hopewell $^{1}$. \\ Elliot J. Carr ${ }^{2} \cdot$ Troy Farrell $^{2} \cdot$ David J. Lee $^{5}$
}

Published online: 22 February 2021

(c) INRAE and Springer-Verlag France SAS, part of Springer Nature 2021

\section{Correction to: https://doi.org/10.1007/ s13595-020-01031-w}

The original article was published with an erroneous affiliation details for co-author, David J. Lee. The correct affiliation for the author is Forest Industries Research Centre, University of the Sunshine Coast, Locked Bag 4, Maroochydore DC, QLD, 4558, Australia.

The original article has been corrected.

The original article can be found online at https://doi.org/10.1007/ s13595-021-01031-w.

Chandan Kumar

chandan.kumar@daf.qld.gov.au

Steven Psaltis

steven.psaltis@qut.edu.au

Henri Bailleres

henri.bailleres@hyn.com.au

Ian Turner

i.turner@qut.edu.au

Loic Brancheriau

loic.brancheriau@cirad.fr

Gary Hopewell

Gary.Hopewell@daf.qld.gov.au

Elliot J. Carr

Elliot.carr@qut.edu.au

Troy Farrell

t.farrell@qut.edu.au
David J. Lee

DLee@usc.edu.au

1 Forest Product Innovation, Department of Agriculture and Fisheries, Queensland Government, Brisbane, Australia

2 School of Mathematical Sciences, Queensland University of Technology, Brisbane, Australia

3 ARC Centre of Excellence for Mathematical and Statistical Frontiers, Queensland University of Technology, Brisbane, QLD 4000, Australia

4 CIRAD, Universite de Montpellier, 34398 Montpellier, France

5 Forest Industries Research Centre, University of the Sunshine Coast, Maroochydore DC, Locked Bag 4, Brisbane, QLD 4558, Australia 